\title{
Sedative-hypnotic like effect of the essential oil from the leaves of Myrtus communis on mice
}

\author{
Muluken Walle ${ }^{1, *}$, Bizuayehu Walle ${ }^{1}$, Legesse Zerihun ${ }^{2}$, Eyasu Makonnen $^{3}$ \\ ${ }^{1}$ Department of physiology, College of medicine and health sciences, BDU, Bahirdar, Ethiopia \\ ${ }^{2}$ Department of Physiology, School of Medicine, AAU, Addis Ababa, Ethiopia \\ ${ }^{3}$ Department of pharmacology, School of Medicine, AAU, Addis Ababa, Ethiopia
}

\section{Email address:}

ninnawal@yahoo.com (Muluken W.)

\section{To cite this article:}

Muluken Walle, Bizuayehu Walle, Legesse Zerihun, Eyasu Makonnen. Sedative-Hypnotic Like Effect of the Essential Oil from the Leaves of Myrtus Communis on Mice. American Journal of Biomedical and Life Sciences. Vol. 2, No. 4, 2014, pp. 70-77.

doi: $10.11648 /$ j.ajbls.20140204.12

\begin{abstract}
Myrtus communis has been recommended for relief of insomnia in Ethiopian traditional medicine and aromatherapy. However, no pharmacological studies have yet evaluated its sedative-hypnotic like effect. The aim of this study was to determine if the essential oil of Myrtus communis has sedative-hypnotic like activity. The essential oil of Myrtus communis $(500,600,800$, and $1000 \mathrm{mg} / \mathrm{kg}$ ) were administered orally to Swiss albino mice of both sex, 60 minutes before pentobarbital injection $(50 \mathrm{mg} / \mathrm{kg})$. Latency to sleep and sleep duration were recorded. More over the effect of the EO on motor-coordination and muscle relaxation were evaluated using Chimney and Traction test 60 and 90 min after administration of the respective doses of the EO respectively. The essential oil prolonged pentobarbital-induced sleeping time at 600,800 (comparable to diazepam $3 \mathrm{mg} / \mathrm{kg}$ ), and at $1000 \mathrm{mg} / \mathrm{kg}$ compared to vehicle-treated group. The $50 \%$ negative response was observed on the Chimney and Traction test at 800 and $1000 \mathrm{mg} / \mathrm{kg}$ respectively. The essential oil of Myrtus communis possesses dose dependent sedative-hypnotic like activity and CNS depressant activity.
\end{abstract}

Keywords: Myrtus Communis, Sedative, Hypnotic, Motor Coordination, Muscle Relaxation, Essential Oil (EO)

\section{Introduction}

Insomnia is a highly prevalent sleep disorder that frequently occurs in its acute form and occurs at a rate of approximately $10-20 \%$ in its chronic form in many countries. And between $26 \%$ and $34 \%$ of the general population suffers from frequent sleeplessness. Sedative-hypnotic drugs, BZDs, Z-drugs and ramelton are the currently used drugs of choice for treatment of insomnia. However newer drugs are needed due to problems of safety, efficacy and duration of treatment on the current medication. Besides, the currently used hypnotics, BZDs, have dependence and tolerance side effects smallest effective dose should be used (Anthony and Walter, 2006). There is also loss of consistency on safety and efficacy of Z-drugs [1]. Moreover, ramelteon which is used for treatment of insomnia associated with sleep onset problem has no effect on sleep duration [2].

In traditional system of medicine, medicinal plants have been used successfully in the management of various diseases. According to a survey of World Health Organization (WHO), the practitioners of traditional system of medicine treat about $80 \%$ of patients. Moreover, nearly $80 \%$ of the global population still depends upon the herbal drugs for their health care. Plant based therapy are marked due to its low cost, easy availability, based on generation to generation knowledge $[3,4]$.

Myrtle (Myrtus communis) is a member of the Myrtaceae plant family which is botanically related to eucalyptus. Myrtle is a native plant of North Africa and is commonly found growing in the southern Mediterranean region including France, Spain, Corsica, Tunisia and Italy. Myrtle is a small tree or large bush (of up to $0.9 \mathrm{~m}$ in height) with pointed leaves, white flowers, and black berries; with aromatic leaves and flowers. Mostly the fresh or dried leaves are used and the dried berry fruits are also aromatic. The leaves have an aromatic and refreshing smell somewhat reminiscent to myrrh or eucalypt; the taste is very intensive, quite disagreeable and strongly bitter $[5,6]$.

In Ethiopia, it is commonly called addus, in Amharic [7]. It is grown in gardens of Addis Ababa. The plant is much 
more wide spread than herbarium collections indicate. This species is used in flavoring butter and also used to extract a perfume which women mix it with butter to make a fragrant ointment for their hair [8].

The most important constituents of myrtle oil (up to $0.8 \%$ in the leaves) are myrtenol, myrtenol acetate, limonene (23\%), linalool $(20 \%)$, pinene $(14 \%)$, cineol $(11 \%)$, furthermore, $p$-cymene, geraniol, nerol and the phenylpropanoid, methyleugenol are also the other constituents. There is considerable variability in the composition of oil from different locations $[9,10,11]$.

Myrtle is better known as a medicinal plant for its anti-hyperglycemic [12], antiseptic and anti inflammatory activities [13].

In Ethiopia it is used for treatment of dandruff, tinea capitis which is called "buha ras" and also as antipyretic substance and as sedative [14]. The leaves and fruits of the plant also mentioned to have vulnerary, cough suppressant, sedative, digestant effects [4]. Different parts of the plant find various uses in food and cosmetic industries [15].

Traditionally, the essential oil from the leaves of Myrtus communis is known to have antiseptic ,bactericidal, anti inflammatory , anti-hyperglycemic, antioxidant, improvement of libido, digestive problems, bronchial congestion, dry coughs, anxiety, epilepsy, mood elevating effect, sedative like effect, antidepressant, antialzhemer's and antiparkinsons like effects [13,14, $16,17,18]$.

Studies were conducted on anti-hyperglycemic, antiseptic and anti-inflammatory effects but not on the CNS effects such as antidepressant and sedative-hypnotic like effects of the essential oil of Myrtus communis [14,19,20].

Therefore, in this study the use of the leave essential oil of Myrtus communis is assessed [13,21].

\section{Materials and Methods}

\subsection{Chemicals}

Chemicals and solvents used include: diazepam. Pentobarbital and 5\% Tween 80 in distilled water (vehicle of the extract).

\subsection{Plant Material Preparation}

Fresh leaves of Myrtus communis were purchased from Merkatto, Addis Ababa. The leaves were detached from the branches and stored in refrigerator until extraction and its botanical identification was confirmed by the National Herbarium, Department of Biology, Faculty of life sciences, Addis Ababa University. It was deposited in the herbarium with a voucher number of 01 .

\subsection{Experimental Animals Preparation}

Male and female Swiss albino mice weighing 18-38 g were obtained from the animal house of Tikur Anbessa Hospital, Faculty of life Sciences, Addis Ababa University, and EHNRI. They were housed in a cage at $21 \pm 1{ }^{\circ} \mathrm{C}$ in a $12-\mathrm{h}$ light/dark cycle in the animal house of Department of
Pharmacology, School of Medicine. Tap water and standard food pellets were available ad libitum. Drug administration and testing of mice were conducted in the Core Lab of The School of Medicine, AAU.

\subsection{Essential Oil Extraction}

The hydro distillation was done in the Drug Formulation Laboratory, EHNRI. Clevenger's type apparatus with a round bottom flask of 5L capacity was used. $2500 \mathrm{gm}$ of the fresh Myrtus Communis leaves were hydro distilled in full glass apparatus of Clevenger's type.

At a time, $500 \mathrm{gm}$ of the leaf was hydro distilled using $2.5 \mathrm{~L}$ of tap water for $3.5 \mathrm{hrs}$ at $30-50^{\circ} \mathrm{C}$ after the water containing the fresh leaves started to boil. The oil was then stored in amber glass bottles in a freezer until used $[9,17]$. Five $\mathrm{ml}$ of the oil was obtained and the percentage yield of the oil from the fresh leaves was $0.18 \%$. The percentage yield of essential oil was determined using the formula described below where the amount of essential oil recovered (g) can be determined by weighing the oil after moisture was removed:

$$
\text { Percentage yield }(\%)=\frac{\text { Amount of essential oil recovered }(\mathrm{g})}{\text { Amount of plant material distilled(100g) }}
$$

\subsection{Grouping and Dosing of Animals}

Three experimental models, used to evaluate the essential oil, were pentobarbital induced sleeping time (PIST), Chimney and Traction test. In PIST model, the mice were divided into six (I-VI) experimental groups of six each. Group I served as a negative control and was given a vehicle, Tween $80(5 \%, \mathrm{v} / \mathrm{v})$ in distilled water. Group II served as positive control and was given standard drug, diazepam $(3 \mathrm{mg} / \mathrm{kg})$, suspended in the vehicle. Groups III - VI p.o.served as test groups and was given the essential oil at doses of 500, 600, 800 and $1000 \mathrm{mg} / \mathrm{kg}$, respectively. Following the oral administration of the different groups, Pentobarbital, $50 \mathrm{mg} / \mathrm{kg}$ were administered i.p. to all groups and their potentiating effect on sleep induced by pentobarbitone was recorded. This was done by recording the latency to sleep and duration of sleep by taking loss and onset of righting reflex as a behavioral marker respectively. Then latency time to sleep, which was the time from administration of the standard pentobarbital, $50 \mathrm{mg} / \mathrm{kg}$ to the loss of righting reflex, was recorded. And the time from offset to the onset of righting reflex was recorded as the duration of sleep. If there was any doubt as to the reappearance of the righting reflex, the mouse was placed gently on its back again and, the righting reflex within one minute was considered as the endpoint. Mean values of duration of anesthesia, pentobarbital (min) was recorded in the control and experimental groups. The percent change in duration of anesthesia was calculated in the experimental groups as compared to those of the controls. And this experiment was repeated three times. All administrations were oral by gavage and the volume administered was $0.5 \mathrm{ml}$.

Similarly, in the Chimney and Traction test, the mice were divided into six (I-VI) experimental groups of six each and 
the mice were dosed orally with the respective doses mentioned above except in Group II, where $1 \mathrm{mg} / \mathrm{kg}$ of diazepam was used as a reference standard.

\subsubsection{Potentiation of Pentobarbital Induced Sleeping Time (PIST)}

This test was the main test used to assess the potentiating effect of substances that prolong sleep induced by hypnotics such as pentobarbital. The body temperature of the mice was maintained at $37^{\circ} \mathrm{C}$ using a lamp. The time from the administration of pentobarbital to loss of righting reflex was recorded to measure the latency to sleep onset. Then the mice were observed to stay on their backs on the pad and the time of regain of the righting reflex was recorded. The time from loss to the regain of the righting reflex was considered as the duration of sleep. The experiment was performed only between 8:00A.M and 6:00P.M.

\subsubsection{Chimney Test}

Male mice weighing between 16 and $30 \mathrm{~g}$ were used in groups of six mice per dose. Pyrex-glass cylinders $30 \mathrm{~cm}$ long of different diameter were used depending on the size of the mice. Initially, the tube was held in a horizontal position. At the end of the tube, near the mark, a mouse was introduced with the head forward. When the mouse reaches the other end of the tube, toward which it was pushed if necessary with a rod, the tube was turned to a vertical position. Immediately, the mouse was observed to climb backwards performing coordinated movements and reach to the mark within $30 \mathrm{sec}$. The time required by the mouse to climb backwards out at the top of the cylinder was recorded. So all mice which were able to perform this activity and reach on the top of the vertically positioned tube with in $30 \mathrm{sec}$ were used in this experiment. After dosing, each mouse was tested on the chimney after $90 \mathrm{~min}$, following administration. To measure motor in coordination (muscle relaxant activity) of drug $\%$ of animals that fail to climb backwards was compared between test and control groups.

\subsubsection{Traction Test}

Male mice with an average weight of 22-30g were used. In a preliminary experiment the mice was tested for their normal reactivity. The mice were exposed to a horizontal thin metallic wire suspended about $30 \mathrm{~cm}$ into the air which they immediately grasp with the forepaws. The mice were released to hang on with its forelimbs. A normal mouse was able to catch the threat with the hind limbs and to go to the other end within $5 \mathrm{~s}$. Only mice that fulfill this criterion was included into the experiment. One hr after dosing, each mouse was subjected to traction test. Mice which were not able to touch the wire with the hind limbs within $5 \mathrm{~s}$ or fall off from the threat were considered to be impaired. In addition, the mice were observed for their behavior in the cages.

\subsection{Statistical Analysis}

For potentiating pentobarbital induced sleeping time, results obtained from behavioral tests were expressed as mean \pm SEM and compared with the corresponding control group by applying ANOVA followed by Dunnet's t-test [22, 23].

For the Chimney test, the $\mathrm{ED}_{50}$ (the dose for which $50 \%$ of the animals fail to climb backwards out of the tube within $30 \mathrm{~s}$, (with $95 \%$ confidence limits) was estimated.

For the traction test, the percentage of animals loosing the catching reflex was calculated. By use of different doses, $\mathrm{ED}_{50}$-value was calculated [22].

The results indicated in all the experiments are analyzed using Microsoft office Excel, 2003 and 2007 soft ware.

\section{Results}

\subsection{Effect of the EO of on Pentobarbital Induced Sleeping Time (PIST)}

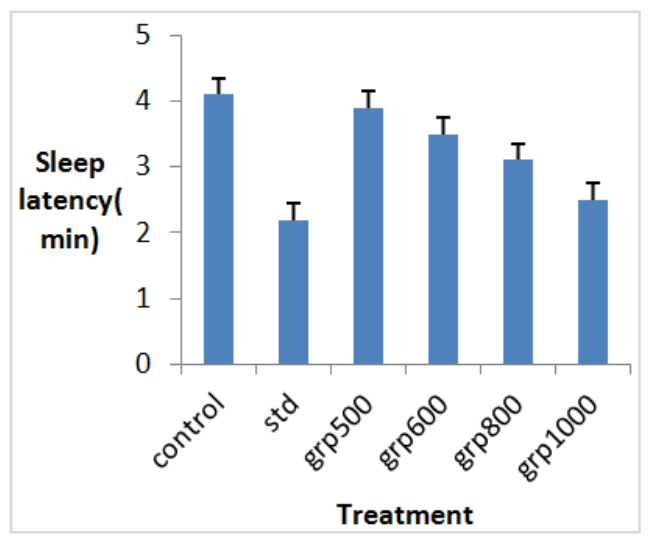

Fig 1A. Effect of EO Myrtus communis leaves on sleep latency in PIST.

(grp500, grp600, grp800, grp1000 P.O); the standard, diazepam (DZ, 3 $\mathrm{mg} / \mathrm{kg}, \mathrm{P} . \mathrm{O}) ; \mathrm{n}=6$ in each group; values represent mean $\pm \mathrm{SEM} ; \mathrm{P}<0.01$ between the test groups and control; $\mathrm{P}<0.001$ between standard and control groups (one-way ANOVA followed by Dunnet's test); std=standard; grp=group administered with the corresponding doses in $\mathrm{mg} / \mathrm{kg}$.)

Pentobarbital had resulted CNS depression and loss of consciousness which was observed by behavioral characteristics such as loss of righting reflex or failure to move up and loss of muscle tone up on laying the mice on their backs on a sleeping pad. Pentobarbital $(50 \mathrm{mg} / \mathrm{kg})$ reduced the locomotory activity to the extent the mice had lost their righting reflex when they were laid on their backs on a pad. The loss of righting reflex was observed in all groups which were treated orally with the vehicle and different doses of the extract and with diazepam following pentobarbital administration. However the time of loss and onset of righting reflex observed were different as shown in the fig.1.A and B. Based on the recorded time of latency and duration to sleep, the mice on the experimental groups reduced latency and increased duration of sleep induced by pentobarbital in a dose dependent manner $(\mathrm{P}<0.01$ between the groups). And the positive control, diazepam also had shown reduced latency and increased duration of sleep induced by pentobarbital on Group II than the control $(\mathrm{P}<0.001)$.

The effect of various doses of the essential oil of the leaves of Myrtus communis on the latency to sleep in the 
Pentobarbital induced sleeping time model is summarized in Fig.1.A. Mice treated with 500, 600, 800 and $1000 \mathrm{mg} / \mathrm{kg}$ of the oil of Myrtus communis were observed to reduce the latency to sleep induced by pentobarbital $(\mathrm{P}<0.01)$ in a dose dependent manner $(3.87,3.52,3.14,2.45 \mathrm{~min}$, respectively) than the control $(4.14 \mathrm{~min})$ though greater than that of the standard (2.16 min).

The effect of various doses of the essential oil of the leaves of Myrtus communis on sleep duration in the PIST model is summarized in Fig.1.B. Mice treated with 500, 600,800 and $1000 \mathrm{mg} / \mathrm{kg}$ of the oil of Myrtus communis were observed to increase the duration of sleep induced by pentobarbital $(\mathrm{P}<0.01)$ in a dose dependent manner $(79.2$, $100.2,150.6,233.9 \mathrm{~min}$, respectively) than the control $(66.2$ $\mathrm{min})$ and comparable to that of the standard (154.5 min).

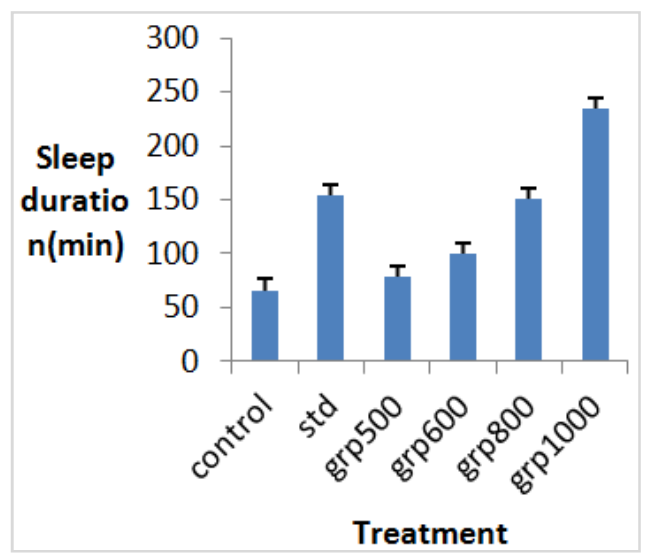

Fig 1B. Effect of the EO of Myrtus communis leaves on sleep duration in PIST

(grp500, grp600, grp800, grp1000 P.O); the standard, diazepam (DZ, 3 $\mathrm{mg} / \mathrm{kg}, \mathrm{P} . \mathrm{O}) ; \mathrm{n}=6$ in each group; values represent mean $\pm \mathrm{SEM} ; \mathrm{P}<0.01$ between the test groups and control; $\mathrm{P}<0.001$ between standard and control groups (one-way ANOVA followed by Dunnet's test); std=standard; grp=group administered with the corresponding doses in $\mathrm{mg} / \mathrm{kg}$.)

\subsection{Effect of the EO on Chimney Test}

The number of animals which showed negative result on the Chimney test following the administration of 500, 600, 800 and $1000 \mathrm{mg} / \mathrm{kg}$ increased in a dose dependent manner $(1,1.5,3,5.5$ respectively) than the control (zero) $(\mathrm{P}<0.01)$. Moreover the inhibition of motor coordination was significant at 600,800 and $1000 \mathrm{mg} / \mathrm{kg} \quad(\mathrm{P}<0.05)$. The standard, diazepam has inhibited the motor coordination of mice (6) than the control (zero) $(\mathrm{P}<0.001)$. And the effect of diazepam, $1 \mathrm{mg} / \mathrm{kg}$ were comparable with $1000 \mathrm{mg} / \mathrm{kg}$ of the EO. Since all the mice treated with diazepam had negative effect for Chimney test, the response was taken as $100 \%$ and percentage of animals that could not climb backwards in the Pyrex glass tube after 30s following the administration of the different treatment groups are summarized in fig.2. More over when the general locomotor activity was observed within the cage after treatment with EO for the Chimney test in their cages, decrease in alertness was observed.

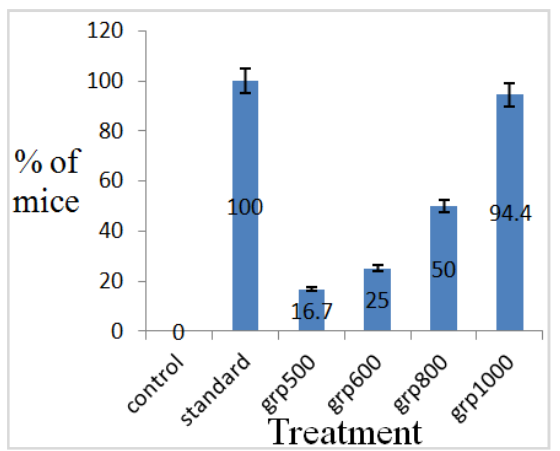

Fig 2. Effect of the EO on the negative response to Chimney test

( $\mathrm{std}=$ Standard, Diazepam $(3 \mathrm{mg} / \mathrm{kg})$; grp=Test group doses $(\mathrm{mg} / \mathrm{kg})$; values represent $\%$ of mice showing negative effects in the tests \pm SEM; $n=6$; $\mathrm{P}<0.01 \mathrm{~b} / \mathrm{n}$ G-III-VI \& G-I; $\mathrm{P}<0.001 \mathrm{~b} / \mathrm{n}$ G-I \& G-II; grp=group administered with the corresponding doses of the EO $(\mathrm{mg} / \mathrm{kg})$, control $=0.4 \mathrm{ml}$ of $5 \%$-tween 80 , standard=Diazepam $(1 \mathrm{mg} / \mathrm{kg})$; Values represent percentages of mice $(n=6)$ showing negative effects in the chimney tests, $1 \mathrm{hr}$ after treatment with the vehicle and EO of varying doses; and 30mins after treatment with the standard, diazepam $1 \mathrm{mg} / \mathrm{kg}$ P.O.)

\subsection{Effect of the EO of on Traction Test}

Their behavior and their motility in the cage were observed to be normal though there was thigmotaxis on the animals on all test groups.

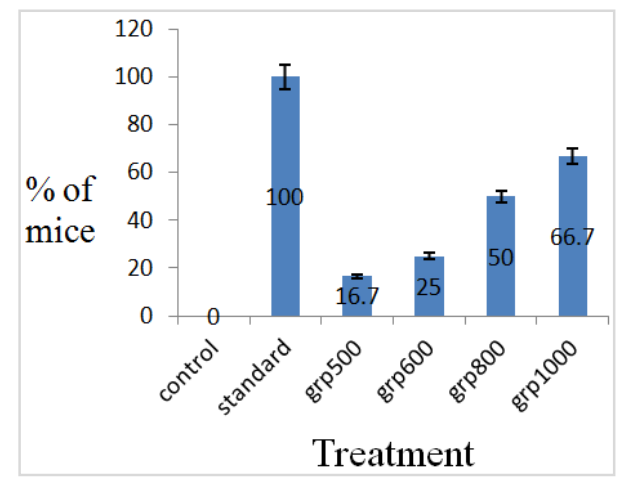

Fig 3. Effect of the EO on the negative response to Traction test

( $\mathrm{std}=$ Standard, Diazepam $(3 \mathrm{mg} / \mathrm{kg})$; grp=Test group doses $(\mathrm{mg} / \mathrm{kg})$; values represent mean $\%$ of mice showing negative effects in the tests $\pm \mathrm{SEM}$; $\mathrm{P}<0.05 \mathrm{~b} / \mathrm{n}$ G-III-VI \& G-I; $\mathrm{P}<0.001 \mathrm{~b} / \mathrm{n}$ G-I \& G-II; $\mathrm{n}=6$ (Values represent percentages of mice $(n=6)$ showing negative effects in the traction tests, $1 \mathrm{hr}$ after treatment with the vehicle and EO of varying doses; and $30 \mathrm{mins}$ after treatment with diazepam. $\mathrm{P}<0.05$ between the test groups and control; $\mathrm{P}<0.001$ between diazepam and control)

The number of animals which showed negative result on the Traction test following the administration of 500, 600, 800 and $1000 \mathrm{mg} / \mathrm{kg}$ increased in a dose dependent manner $(1,1.5,3,5.5$ respectively) than the control (zero) $(\mathrm{P}<0.01)$. Moreover the negative result on the Traction test was significant at 600,800 and $1000 \mathrm{mg} / \mathrm{kg}(\mathrm{P}<0.05)$ than the control. The standard, diazepam has negative result on the Traction test of mice (6) than the control (zero) $(\mathrm{P}<0.001)$. Since all the mice treated with diazepam have negative effect for Traction test, the response was taken as $100 \%$ and 
percentage of mice that could not place at least one hind foot on the wire within $5 \mathrm{~s}$, following the administration of the different treatment groups are summarized in fig.3.

\section{Discussions}

Despite the widely popular use of Myrtus communis for various purposes, there is an absence of scientific reports about evaluation of its pharmacological effects as as sedative-hypnotic. In this work, it was demonstrated that administration of different doses of the essential oil of Myrtus communis in mice prolonged hypnotic effects induced by pentobarbital, in a dose dependent manner. Moreover the general observation of the mice in their cages after administration of the varying doses of the oil indicated there was thigmotaxis and these mice had greater tendency to remain to the walls of the cages than those in the control group. The Chimney and Traction test results revealed that there was significant association between the CNS depressant effect and increasing doses of the EO administered. The oil also showed that there was reduction on the onset and increment in duration of sleep in pentobarbital induced sleep. The present finding also indicated that the oil possesses sedative- hypnotic like effect.

The inhibition of motor coordination is possibly mediated through the $\mathrm{GABA}_{\mathrm{A}}$ /benzodiazepine and glycine inhibitory mechanisms [24]. Moreover, the effect of hypnotics on sleep pattern of EEG tracings can be studied in the future on conscious, freely moving animals with chronically implanted electrodes to observe the effect of the EO on REM and NREM sleep (Vogel, 2002). This study has proved the sedative-hypnotic like activity of the EO of Myrtus communis and promotes the traditional use of the plant for treatment of insomnia though direct extrapolation of the effective doses is not possible as the routes of administration are different. More over it gives appraisal to herbal medicine as $80 \%$ of the developing world population relies on herbal medicine [4].

The PIST test was used to elucidate CNS depressant properties of drugs. Not only hypnotics, sedatives, and tranquilizers but also antidepressants at high doses are known to prolong pentobarbital induced sleep [25]. The loss of righting reflex is measured as criterion for the duration of pentobarbital-induced sleeping time as it was done in previous studies [26]. Barbiturates have hypnotic and anesthetic effect indicating an interesting potential connection between anesthesia and sleep [26]. Compounds with sedative activity may produce depressant effect like relaxation in muscular activity (motor in coordination) as previous studies show [27]. And in this study significance association between inhibition of motor activity and the different doses of the EO were observed indicating CNS depressant activity of the EO.

\subsection{Effects of the EO on PIST}

In this study, significant potentiation of the sleep duration induced by pentobarbital was observed and the duration was increased as the dose of the EO was increased from 500 to $1000 \mathrm{mg} / \mathrm{kg}$. The essential oil of the leaves of Myrtus communis produced a substantial dose-related potentiation of the hypnotic effect induced by pentobarbital. It potentiated the pentobarbital-induced sleep by shortening the induction time and prolonging the sleep duration.

Similarly hypnotic potentiating effect of essential oil Zanthoxylum budrunga and high dose of the aqueous extract of Coriander seeds based on potentiation of thiopental and pentobarbital induced sleeping and latency time was used to study the effect of plant materials on sleep $[27,28]$. Moreover, the commonly used hypnotics do increase total sleep time, decrease sleep latency and decrease the number of awakenings [29].

Although significant potentiation of hypnotic activity induced by pentobarbital was observed, PIST model was considered to be unspecific [25] i.e. it's difficult to predict whether the potentiation is caused by pharmacokinetic or pharmaodynamic interaction between the EO and pentobarbital. But still there were some indications which favor the interaction to be pharmaodynamic. The different routes of administration of the EO (P.O.) and pentobarbital (i.p.) may rule out the possibility of interaction at the level of absorption. Moreover as acute toxicity studies showed that the EO induced liver metabolizing enzymes [30], the possibility of interaction at the level of biotransformation could also be ruled out. For potentiation to occur at this level there must be enzyme inhibition as in the case of $\mathrm{CCl} 4$ which prolonged the pentobarbital sleeping time in rats [22] suggesting CNS depressant activity of the EO Myrtus communis. The possible interactions at the levels of distribution and excretion, however, are still there which might need further investigations.

It is known that benzodiazepines have anxiolytic effect at low doses and possess hypnotic effects at higher doses. The essential oil of the leaves of Myrtus communis at $400 \mathrm{mg} / \mathrm{kg}$ was shown to have anxiolytic effect in mice in one of the previous studies $[7,31]$. These suggest that phamacologic profile of the essential oil of the leaves of Myrtus communis might resemble that of other hypnotics, BZDs or barbiturates. Barbiturates and BZDs are known to have sedative and hypnotic effects at low and higher dose, respectively.

In the present study, the routes of administration of essential oil of Myrtus communis were p.o., which was different from its traditional route, inhalation, in humans. Since the difference in route of administration may affect the pharmacokinetics of the active components, the therapeutic doses and the extent of hypnotic like effect of the Myrtus communis EO preparations obtained here cannot be extrapolated to human. However, these results support the traditional use of EO of Myrtus communis as a hypnotic medicine and its potential use for treatment of insomnia.

Previous studies have reported $\alpha$-pinene, limonene and linalool, to be the major monoterpinoids of the essential oil of the leaves of Myrtus communis [32]. And in literatures linalool, is shown to have sedative and anticonvulsant activity in animal studies, anxiolytic and sedative activity in 
human studies. The other monoterpinoids such as limonene and Mercene were also shown to possess sedative and muscle relaxant effects in mice. Therefore these monoterpinoids may also be responsible for the observed hypnotic like and CNS depressant effects of the EO of Myrtus communis. In other studies it has been reported that Sapindus emarginatus contains triterpenoids and saponins which produce CNS depressant action and number of scientific reports indicated that triterpenoids produced CNS depressant action [33].

The mechanism by which the EO of the leaves of Myrtus communis exerts its effects has to be addressed in future studies. Compounds that act through GABA-chloride ion channel complex prolonged pentobarbital induced sleep duration, and reduced the latency to sleep [26, 31, 34]. Therefore, an involvement of GABA ergic system may be suggested though future studies using flumazenil, a benzodiazepine receptor antagonist, is essential to address this possibility.

In this study, significant hypnotic like effect was observed and the duration of sleep was increased as the dose of the EO was increased from 800 to $1200 \mathrm{mg} / \mathrm{kg}$. More over latency to sleep was decreased significantly by the EO in a dose dependent manner. Therefore, the present findings indicate hypnotic like effect.

In agreement with the previously published reports, pentobarbital produced hypnosis at $50 \mathrm{mg} / \mathrm{kg}$ [22]. Likewise barbiturates and BZDs have shown to depress the CNS in a dose dependent manner producing sedation, sleep, unconsciousness and surgical anesthesia [31].

In previous studies, linalol, pinene, citral, limonene are believed to be responsible components for hypnotic effect of essential oil of Zanthoxylum budrunga [27]. The hypnotic activity the EO of Myrtus communis might as well be due to these compounds as these chemicals are also present in the EO of Myrtus communis [11].

In this study the EO of Myrtus communis has shown to have potential uses for treatments of insomnia as claimed in CAM. However the difference in dosage regimen should be considered, typically in repeated or chronic intake when the population uses the infusion, as opposed to acute treatment employed in this experiment.

\subsection{Effects of the EO in Chimney and Traction Tests}

In this study significant association between the doses of the EO of Myrtus communis and decreased neuromuscular coordination and muscle relaxant activity which indicates the CNS depressant effects of EO of the leaves of Myrtus communis. Experimental results show that the EO produced a significant skeletal muscle relaxation and $50 \%$ of the mice were observed to respond at doses of $800 \mathrm{mg} / \mathrm{kg}$ and $1000 \mathrm{mg} / \mathrm{kg}$ for negative responses to Chimney and Traction test respectively.

Likewise, to measure motor in coordination effect of the essential oil of Coriander seeds \% of animals that fall from rod was compared between test and control groups though the equipment used here is Rota rod [11,27].
Though there was significant muscle relaxant activity, none of the administered doses were comparable to that of diazepam as $50 \%$ negative response was observed in the higher dose $(1000 \mathrm{mg} / \mathrm{kg})$ of the EO on traction test. However, muscle relaxation is could not be a characteristic of some other preferred hypnotics like zolpidem, zaleplon and zopiclone though these drugs are hypnotics [1].

In this study, the essential oil was observed to induce and prolong sleep, and potentiate sleep duration induced by pentobarbital and inhibit skeletal muscle contraction and motor coordination in dose dependent manner; the EO of Myrtus communis might have also similar mechanisms of action like the benzodiazepines or barbiturates.

These effects are in line with the behavioral response of hypnotics in animal experiments, characterized by deeper stage of central depression of drug induced unconsciousness associated with loss of muscle tone and of righting reflexes [22].

In this study, the potential use of the EO of the leaves of Myrtus communis for treatment of insomnia is proved as it has mild hypnotic like effect. This plant should be promoted as the prevalence of insomnia in the general population (26-34\%) makes it one of the common disease conditions [1, 35].

Previous studies also indicate that plants with hypnotic activity like, Hypericum perforatum are observed to prolong duration of deep sleep and treat depression co morbid insomnia [3].

In previous studies, EEG recordings were used to observe the hypnotic effect of Hypericum perforatum and Valerian on sleep showed increase in duration of deep sleep and modulation of REM [29]. Hence, future scientific investigations using EEG recordings should be done to observe the effect of the EO on sleep stages and cortical arousal.

\section{Conclusions}

This study, deploying different animal models of sedative-hypnotics, significantly supports the Ethiopian traditional medicine claim that the essential oil of Myrtus communis can be used for insomnia. The EO of Myrtus communis prolongs sleep duration and reduces sleep latency in mice. In addition, the EO depresses CNS activity as shown from the negative results in the Chimney and Traction tests. Myrtus communis may be considered as an alternative for the treatment of insomnia to other medications currently used as the oil appears to be well tolerated in mice even at higher doses.

\section{Recommendations}

Based on the present studies the following investigations are recommended to be carried out in the future:

- Further evaluations are required to elucidate the detailed mechanism of the hypnotic action of the oil using flumazenil, a benzodiazepine receptor 
antagonist.

- $\quad$ Further work is required to test the hypnotic effects of the major fractions of the oil.

- It may be necessary to use different animal models to study the hypnotic effect of the essential oil of Myrtus communis such as locomotory activity tests.

- $\quad$ Further study using the essential oils of Myrtus communis should be carried out to study some of the reported pharmacological activities in aromatherapy such as epilepsy and depression.

- It may also be essential to test the non-volatile extracts of Myrtus communis.

- Electrophysiological investigations such as brain EEG analysis or EMG analysis should be done.

\section{Conflict of Interest}

There are no conflicts of interests on this research work.

\section{Acknowledgments}

We appreciate the contribution of the Department of physiology and pharmacology of school of medicine of AAU and EHNRI; and BDU for all the assistance towards the success of the study.

\section{List of Abbreviations}

$\begin{array}{ll}\text { AAU } & \text { Addis Ababa University } \\ \text { BDU } & \text { Bahir Dar University } \\ \text { BZDs } & \text { Benzodiazepines } \\ \text { CAM } & \text { Complementary and Alternative Medicine } \\ \text { CNS } & \text { Central Nervous System } \\ \text { EEG } & \text { Electroencephalogram } \\ \text { EHNRI } & \text { Ethiopian Health and Nutrition Research } \\ \text { EMG } & \text { Institute } \\ \text { EO } & \text { Electro Myo Gram } \\ \text { GABA } & \text { Gamma Amino Butyric Acid } \\ \text { NREM } & \text { Non Rapid Eye Movement } \\ \text { NIH } & \text { National Institute of Health } \\ \text { PIST } & \text { Potentiation of Pentobarbital Induced } \\ \text { REM } & \text { Sleeping time } \\ & \text { Rapid Eye Movement }\end{array}$

\section{References}

[1] Gary K. ( 2007). The Prevalence, Morbidities, and Treatments of Insomnia. CNS \& Neurological Disorders Drug Targets. 6: 3-16.

[2] NPC, National Prescribing Centre Data focused commentary. (2010). Insomnia: Data focused commentary.

[3] Wing Y. (2001). Herbal treatment of insomnia. HKMJ, 7:392-402.

[4] Tiwari S. (2008). Plants: A Rich Source of Herbal Medicine. Journal of Natural Products: 1:27-35..
[5] Travese. (2001). Ecology of Fruit-color Polymorphism in Myrtus communis and Differential Effects of Birds and Mammals on Seed Germination and Seedling Growth, in Journal of Ecology., 89: 749-760.

[6] Aronne De Micco. (2004). Hypocotyl features of Myrtus communis (Myrtaceae): a many-sided strategy for possible enhancement of seedling establishment in the Mediterranean environment, in Botanical Journal of Linnean Society, 145: 195-202.

[7] Eyob H. (2010).Anxiolytic effect of the extract of Myrtus communis.

[8] Mesfin T., Hedberg I. (1995). Flora of Ethiopia and Eritrea. 2:71-73.

[9] Appendino G. (2002). Oligomeric acylphloroglucinols from myrtle (Myrtus communis). J. Nat. Prod., 65:334-338.

[10] Cakir A. (2004). Essential oil and fatty acid composition of Hippophae Rhamnoides L., and Myrtus communis L. from Turkey. Biochem. Syst. Ecol. 3:809-816.

[11] Stefania Z., Sara C., Paola M., Alessandra B., Marina C., Silvia P., Bruno M., Leonardo A. (2010). Evaluation of the Antimicrobial Properties of the Essential Oil of Myrtus communis L. against Clinical Strains of Mycobacterium spp. doi: 10:1155-931530.

[12] Elfellah M., Akhter M., Khan M. (1984). Anti-hyperglycemic effect of an extract of Myrtus communis in streptozotocin induced diabetes in mice. $J$. Ethnopharmacol., 11: 275-281.

[13] Al-Hindawi M. (1989). Anti inflammatory activity of some Iraqi plants using intact rats. Journal of Ethnopharmacology, 26:163-168.

[14] Jansen, PCM. (1981) Spices, Condiments and Medicinal Plant in Ethiopia, their taxonomy and Agricultural Significance. Centre for Agricultural Publishing and Documentation, Wageningen, the Netherlands. 274.

[15] Chalchat J. (1998). Essential oils of Myrtle (Myrtus communis L.) of the Miterranean littoral. Journal of Essential Oil Research, 10:613-617.

[16] Health world. (2010) .http:/www.desert-tropicals.com( last retrieved on January 3, 2010.

[17] Shron.,http://www.ehealthyland.com/health/essential-oil/my rtle-essential-oil-health-benefits.html (last retrieved on January 29, 2010.

[18] Suite101http://aromatherapy.com/article.cfm/myrtle_essenti al_oil (last retrieved on January 15, 2010).

[19] Mansouri S., Foroumadi A., Ghaneie T., Najar A. (2001). Antibacterial activity of the crude extracts and fractionated constituents of Myrtus communis. Pharm. Biol. 39, 399-401.

[20] Chryssavgi G., Vassiliki P., Athanasios M., Kibouris T., Komaitis M. (2008). Essential oil composition of Pistacia lentiscus and Myrtus communis L: Evaluation of antioxidant capacity of methanolic extracts. Food Chem. 107: 1120-1130.

[21] Rainer W., Peter K. (2008). The Homeopathic Preparation Neurexan ${ }^{\circledR}$ vs. Valerian for the Treatment of Insomnia: An Observational Study. The Scientific World JOURNAL., 8: 411-420. 
[22] Vogel H., Wolfgang J., Scholkens A., Sandow J.,Muller G., Vogel F.(2002). Hypnotic activity. Drug Discovery and Evaluation Pharmacological Assays, 2:495-496.

[23] Balamurgan K., Akalanka D., Sivakumar G.(2007). Some neuropharamacological effects of the crude extract of Conus Parvatus in mice. Pak. J. Biol. Sci., 10: 4136-4139.

[24] Möhler H., (2002). A new benzodiazepine pharmacology. $J$ Pharmacol Exp Ther., 300:2-8

[25] Fujimori H. (1965). Potentiation of barbital hypnosis as an evaluation method for central nervous system depressants. Psychopharmacologia. 7:374-378.

[26] Nelson L. (2002). The sedative component of anesthesia is mediated by $\mathrm{GABA}(\mathrm{A})$ receptors in an endogenous sleep pathway. Nat Neurosci., 5:979-984.

[27] Upendra B., Akash Y., Navneet A., Durga J., Indranil K., Yari P., Dinesh C., Jain A., (2009). Hypnotic effect of essential oil and methanolic extract of fruits of zanthoxylum budrunga $\mathrm{w}$. IJPRIF (1) 4:1494-1498.

[28] Emamghoreishi M., Heidari-Hamedani G. (2006). Sedative-Hypnotic Activity of Extracts and, Essential Oil of Coriander Seeds. Iran J Med Sci., (1)31: 22-27.

[29] Alexander A., Torbjiirn k., Odile B., Florian H., Ian O. (1991).
Hypnotics and Sleep Physiology: A Consensus Report. Eur. Arch Psychiatry Clin. Neurosci., 241: 13-21.

[30] Hartmut U. (1979). Oral toxicity of an essential oil from myrtle and adaptive liver stimulation. Toxicology 12(3): 335-342.

[31] Dennis S., Charney S., John M., Adron H. (2006). Hypnotics and sedatives. In Goodmans and Gilmans, the pharmacological basis of therapeutics. 11(16): 401-429.

[32] Ramanathan S., Shanmuga R., Sivakumar P., Nethaji R., Senthil V., Venkateswara N., Kanagasabi R. (2008). CNS activity of the methanol extracts of Careya arborea in experimental animal model. Bangladesh J Pharmacol., 3: 36-43.

[33] Srikanth J., Muralidharan P. (2009). CNS Activity of the Methanol Extracts of Sapindus emarginatus Vahl in Experimental Animal Models. J. Sci. Res., 1 (3): 583-593.

[34] Hall. (1988). The anesthetic efficacy of midazolam in enfluraneanesthetized dog. Anesthesiology 68:862-866.

[35] Wilfred R., (2010). Diagnosis, prevalence, pathways, consequences \& treatment of insomnia. Indian $\mathrm{J}$ Med Res 131: $321-332$ 